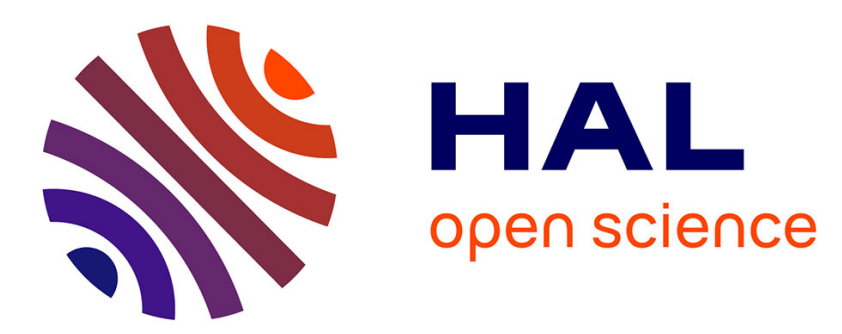

\title{
Effects of turbulence on alkaline phosphatase activity of phytoplankton and bacterioplankton in Lake Taihu
} Jian Zhou, Boqiang Qin, Céline Casenave, Xiaoxia Han

\section{To cite this version:}

Jian Zhou, Boqiang Qin, Céline Casenave, Xiaoxia Han. Effects of turbulence on alkaline phosphatase activity of phytoplankton and bacterioplankton in Lake Taihu. Hydrobiologia, 2016, 765 (1), pp.197207. 10.1007/s10750-015-2413-z . hal-01196465v2

\section{HAL Id: hal-01196465 \\ https://hal.science/hal-01196465v2}

Submitted on 11 Jan 2016

HAL is a multi-disciplinary open access archive for the deposit and dissemination of scientific research documents, whether they are published or not. The documents may come from teaching and research institutions in France or abroad, or from public or private research centers.
L'archive ouverte pluridisciplinaire HAL, est destinée au dépôt et à la diffusion de documents scientifiques de niveau recherche, publiés ou non, émanant des établissements d'enseignement et de recherche français ou étrangers, des laboratoires publics ou privés. 


\title{
Effects of turbulence on alkaline phosphatase activity of phytoplankton and bacterioplankton in Lake Taihu
}

\author{
Jian Zhou ${ }^{1,2}$, Boqiang Qin ${ }^{1 *}$, Céline Casenave ${ }^{3}$, Xiaoxia $\operatorname{Han}^{4}$
}

1: State Key Laboratory of Lake Science and Environment, Nanjing Institute of Geography and Limnology, Chinese Academy of Sciences, 73 East Beijing Road, Nanjing, 210008, P. R. China

2: University of Chinese Academy of Sciences, Beijing, 100049, P. R. China

3: UMR INRA-SupAgro 0729 MISTEA (Mathematics, Informatics and Statistics for Environment \& Agronomy), 2 place Pierre Viala, 34060 Montpellier, France

4: College of Resources and Environmental Sciences, Nanjing Agricultural University, Nanjing 210095, P.

R. China

${ }^{*}$ Corresponding Author: Boqiang Qin

E-mail: qinbq@niglas.ac.cn

Tel: +86-025-86882192; Fax: +86-025-57714759

Abstract: Alkaline phosphatase (AP), an inducible and hydrolytic enzyme, plays a key role in the biogeochemical cycle of phosphorus (P) in lakes. Activity and regulation of AP has been suggested to be affected by hydrodynamic turbulence. However, many aspects of the coupling of the AP activity (APA) and turbulence are still to be investigated and understood. In this study, mesocosm experiments were carried out to further understand the effects of turbulence on APA and the relative contribution of the different microbial groups to the total APA (TAPA). Specifically, we focused on evaluating the APA of phytoplankton $(2-112 \mu \mathrm{m})$ and bacterioplankton $(0.2-2 \mu \mathrm{m})$ and its relationship with $\mathrm{P}$ fractions under four turbulence levels. Results showed that turbulent conditions enhanced planktonic APA (PAPA) which dominated TAPA by comprising 66-93\% of the total fraction. In particular, PAPA was almost two times higher in the turbulence treatments than in still-water control. On the other hand, bacterioplanktonic APA (BAPA) decreased which could be associated with the competitive advantage of bacteria in nutrient limited conditions due to surface to volume ratio. The results suggest that turbulence can accelerate the biogeochemical cycle of $\mathrm{P}$ and plays an important role in $\mathrm{P}$ strategies of plankton.

Keywords: Turbulence · Alkaline phosphatase activity · Phytoplankton · Bacterioplankton · Phosphorus deficiency · Phosphorus strategy 


\section{Introduction}

Phosphorus (P) is one of the essential elements for all living organisms (Istvánovics, 2008), but its low availability often constrains the growth and/or biomass of aquatic biota (Carpenter, 2008). Inorganic phosphate (Pi) is generally regarded as directly available and most rapidly assimilated by plankton (Currie \& Kalff, 1984b). However, the quantity of Pi is often insufficient to satisfy the demand of phytoplankton in lakes (Wetzel, 2001; Gao et al., 2006; Nedoma et al., 2006). The underlying mechanisms involved and the rate of $\mathrm{P}$ regeneration are therefore some of the important factors that control nutrient status and primary productivity of lakes (Jansson et al., 1988). One of the significant ways to regenerate is through the decomposition of organic matter by enzymes. Particularly, the enzyme alkaline phosphatase (AP) is responsible for the hydrolysis of dissolved organic phosphorus (DOP) to compensate for the lack of $\mathrm{P}$ (Labry et al., 2005).

$\mathrm{AP}$ as a hydrolytic enzyme can split phosphate-monoester bonds of organic $\mathrm{P}$ and release $\mathrm{Pi}$ at alkaline pH (Tanaka et al., 2008). Its role in the biogeochemical cycle of $\mathrm{P}$ has been confirmed by numerous studies (Labry et al., 2005; Dyhrman \& Ruttenberg, 2006; Raheb et al., 2006; Cao et al., 2009b). Alkaline phophatase activity (APA) is generally regulated by external Pi concentration (Tanaka et al., 2008;). Also, several studies indicated that cellular (phosphorus cell quota) rather than external phosphorus controlled APA (Litchman \& Nguyen, 2008; Meseck et al., 2009; Cao et al., 2010). As an inducible enzyme, the level of APA can therefore be used as a convenient indicator of P deficiency, although several studies also observed that the relationship between APA and P concentration was random or insignificant in some aquatic systems (Jamet et al., 1997; Cao et al., 2009a). Most studies have shown that phytoplankton and bacteria are the most known to have significant APA (Labry et al., 2005; Nedoma et al., 2006; Cao et al., 2009b), however, some evidence also suggest that AP can also be released by large zooplankton (Jansson et al., 1988). Most papers have evaluated the total APA on unfiltered samples or separate particulate and dissolved APA, considering that algae or bacteria represent the bulk of particulate APA (Labry et al., 2005; Dyhrman \& Ruttenberg, 2006). Other studies also evaluated APA from plankton fractions, specific phytoplankton species or even individual cells (Rengefors et al., 2001; Hernandez et al., 2002; Raheb et al., 2006). Even if size fractionation by filtration is never completely absolute (i.e. overlapping size), it still provides useful insights on the major microorganisms possibly contributing to APA. However, surveys dealing with simultaneous fractionation of algal and bacteria are relatively scarce (Labry et al., 2005).

Hydrodynamic turbulence is an intrinsic and ubiquitous characteristic of aquatic environments, especially for the large shallow lakes which are strongly influenced by wind waves (Cardoso \& Marques, 2009). It has been shown that turbulence can accelerate nutrient transport toward a cell and enhance nutrient uptake, especially at low nutrient levels (Barton et al., 2014). Generally, in lakes, P is considered as the limiting factor for phytoplankton growth (Labry et al., 2005; Dyhrman \& Ruttenberg, 2006; Tanaka et al., 2006; Tanaka et al., 2008). As an inducible and hydrolytic enzyme, AP plays an important role in phosphorus recycling process when Pi is low in lakes. Therefore, because water turbulence is important in nutrient uptake, the expression of APA may also be related to it. Unfortunately, the direct relationship between these two significant variable, turbulence and APA, are rarely explored in lake waters.

Lake Taihu (Taihu) is the third largest freshwater lake in China, with a total area of 2,338 $\mathrm{km}^{2}$ (Qin et al., 2007). It is a typical shallow eutrophic lake, with an average depth of $1.9 \mathrm{~m}$ and a maximum depth of $2.6 \mathrm{~m}$, thus, it is strongly influenced by wind waves (Qin et al., 2007). However, dense surface harmful cyanobacterial blooms of the cyanobacterium Microcystis have occurred every summer for the past thirty years, even though the Pi levels of aquatic were very low (Qin et al., 2010). The ability of the cyanobacteria to survive in nutrient-limited environment suggest abilities to adapt to such scenarios, one unexplored possibility is the regulation of AP to survive non-optimal conditions. Interestingly, wind waves were suggested to an important variable that allowed formation and expansion of cyanobacterial blooms in Taihu (Wu et al., 2013; Zhu et al., 2014).

In this study, we hypothesize that there is a link between turbulence and APA, and that this coupling has significant implications to the growth of some groups of algae (i.e. cyanobacteria) during 
nutrient starvation. To further investigate and provide evidence to such questions, a mesocosm experiment was carried out. Specifically, this study aims to 1) better understand the nutrient strategies of phytoplankton and bacterioplankton in turbulent environments, and 2) investigate the effects of turbulence on APA of the two planktonic groups.

\section{Materials and Methods}

\section{Experimental setup}

A total of twelve (12) units of customized tanks made of $8 \mathrm{~mm}$ thick Plexiglass and have maximal capacities of $126 \mathrm{~L}$ (Fig. 1) were used for the mesocosm experiments. Artificial waves were generated by frequency conversion wave-maker pumps (WP, Jebao, China), and rebounds were reduced by the slopes (5:1) on the sides (Fig. 1 a) where energy dissipation plates are also fixed (Fig. 1 b). Chemical contamination from the material was avoided by immersing the tanks in water for 15 days before being used for any experiment.
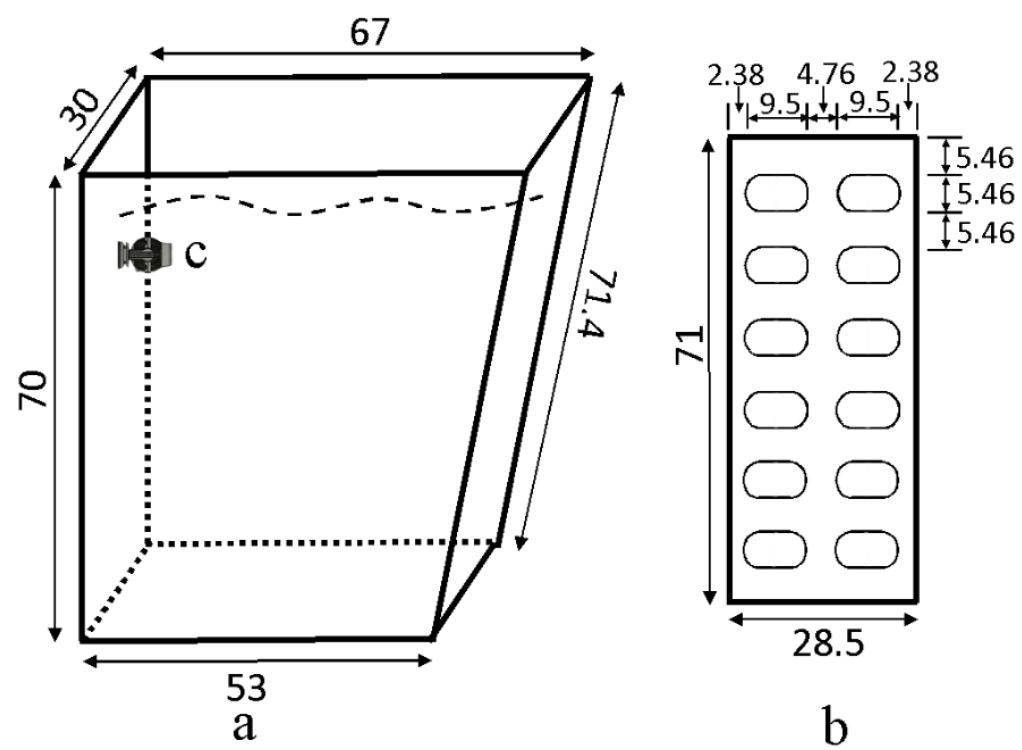

Fig. 1 Diagram of the mesocosm tank (a) used in the experiments which includes an energy dissipation plate (b) and a wave-maker pump (c). All dimensions are in centimetre.

\section{Experimental design}

Experiments were only conducted for 9 days to lessen potential variances caused by bottle effects. The bioassay experiments were performed from the $7^{\text {th }}$ to the $16^{\text {th }}$ of July 2014 at TLLER (Taihu Laboratory for Lake Ecosystem Research, Chinese Academy of Science) on the shores of Lake Taihu, in Wuxi. A total of $96 \mathrm{~L}$ of lake's subsurface water $(<0.2 \mathrm{~m})$ was filled in the tank. The tanks were then floated and fixed in an outside artificial pond $(10 \times 10 \times 2 \mathrm{~m})$ which was filled with lake water and dug 1 $\mathrm{m}$ into the ground to simulate natural conditions. Since adhesion of microorganisms could occur and affect the result, the inside walls of each tank (except the bottom) were also gently brushed at 6:30 p.m. every day.

\section{Turbulence generation}

The submerged wave-maker pumps described earlier, fixed under surface water by strong magnets, were used to generate turbulence simulate to the ones induced by natural wind waves as demonstrated in previous studies (Clarke et al., 2005; Pekcan-Hekim et al., 2013; Härkönen et al., 2014).

The pump frequency was set to $1 \mathrm{~Hz}$ and the turbulence generated was monitored and measured by an acoustic Doppler velocimeter (ADV, 10 MHz ADVField; Sontek/YSI, San Diego, California, USA). The turbulence intensity was measured from the middle of the tank with a $25 \mathrm{~Hz}$ measurement for a period of 2 
min. Measurements were performed after the turbulent motion in the tank had reached a steady state (after 6-7 min).

To define the characteristic speed of the turbulence, the root mean square (RMS) velocity (cm s${ }^{-1}$ ) was calculated by using the following formula:

where

$$
R M S=\sqrt{\mu_{R M S_{x}}{ }^{2}+\mu_{R M S_{y}}{ }^{2}+\mu_{R M S_{z}}{ }^{2}}
$$

$$
\mu_{R M S_{x}}=\sqrt{\frac{\sum \mu_{x}^{2}-\left(\sum \mu_{x}\right)^{2} / n}{n-1}}
$$

is the fluctuation of the flow for Cartesian vector $x$ (which is similarly calculated for the $y$ and $z$ vectors) and $n$ is the number of samples per measurement. The RMS velocities were expressed as averages for the whole tank. The energy dissipation rate $\left(\varepsilon, \mathrm{m}^{2} \mathrm{~s}^{-3}\right)$, which describes the rate at which the turbulent energy decays over time, was deduced from the RMS velocity $\left(\mathrm{m} \mathrm{s}^{-1}\right)$ following the formula described by Sanford (1997):

$$
\varepsilon=A_{1} \frac{R M S^{3}}{l}
$$

where $A_{1}$ is an dimensional constant of order 1 (Kundu \& Cohen, 2010), and $l$ is the water depth (m) describing the size of the largest vortices.

The Reynolds number (Re, the ratio of inertial forces to viscous forces) for the given turbulence levels was calculated following Peters \& Redondo (1997):

$$
R e=\frac{R M S l}{v}
$$

where $l$ is the water depth $(\mathrm{m})$ and $v$ is the kinematic viscosity for water $\left(8.5 \times 10^{-7} \mathrm{~m}^{2} \mathrm{~s}^{-1}\right)$.

Table 1 Summary of the root mean square (RMS) velocities, energy dissipation rates $(\varepsilon)$, and Reynolds numbers $(R e)$ of the four levels turbulence (treatments) used in the experiments which include the (1) control (calm water), (2) low, (3) medium and (4) high turbulence intensities.

\begin{tabular}{llll}
\hline Turbulence level & RMS velocity $\left(\mathrm{cm} \mathrm{s}^{-1}\right)$ & $\varepsilon\left(\mathrm{m}^{2} \mathrm{~s}^{-3}\right)$ & $R e$ \\
\hline Control & 0 & 0 & 0 \\
Low & 0.85 & $1.12 \times 10^{-6}$ & 5500 \\
Medium & 2.53 & $2.95 \times 10^{-5}$ & 16371 \\
High & 4.33 & $1.48 \times 10^{-4}$ & 92620 \\
Lake Taihu & $0.49 \sim 7.69$ & $6.01 \times 10^{-8} \sim 2.39 \times 10^{-4}$ & $2882 \sim 180941$ \\
\hline
\end{tabular}

The different levels of turbulence intensities used in this study were based on actual conditions previously observed in Lake Taihu on summer 2013. In Taihu, the $\varepsilon$ varied between $6.01 \times 10^{-8}$ and $2.39 \times$ $10^{-4} \mathrm{~m}^{2} \mathrm{~s}^{-3}$ (Table 1), which corresponded to the range of values (from $1.07 \times 10^{-7}$ to $6.67 \times 10^{-3} \mathrm{~m}^{2} \mathrm{~s}^{-3}$ ) previously measured by G.-Tóth et al. (2011) in the large shallow Lake Balaton. The calm condition $(0 \mathrm{~cm}$ $\mathrm{s}^{-1}$ ) which is without any hydrodynamic turbulence was the control. The other 3 RMS velocities which also correspond to the different turbulent intensities used in the experiments were $0.85 \mathrm{~cm} \mathrm{~s}^{-1}$ (low), 2.53 $\mathrm{cm} \mathrm{s}^{-1}$ (medium) and $4.33 \mathrm{~cm} \mathrm{~s}^{-1}$ (high). These intensities have corresponding $\varepsilon$ ranging from $1.12 \times 10^{-6}$ to $1.48 \times 10^{-4} \mathrm{~m}^{2} \mathrm{~s}^{-3}$ with Re between 5500 and 92620 in Taihu (Table 1). All treatments were conducted in triplicate.

\section{Measurements}

Physico-chemical parameters were measured every day from day 0 to day 9, between 7:00 and 8:00 in the morning. Water temperature (WT), dissolved oxygen (DO) and pH were determined using a 6600 
multi-sensor sonde (Yellow Springs Instruments, San Diego, California, USA). Nutrients were also analyzed including total nitrogen (TN), total dissolved nitrogen (TDN), total phosphorus (TP), total dissolved phosphorus (TDP), and phosphate (Pi), following the methods described in Zhu et al (2014). The particulate fractions of nitrogen (PN) and phosphate (PP) were obtained by subtracting the TDN/P from the TN/P. On the other hand, the dissolved organic phosphorus (DOP) was estimated from difference of the Pi from the TDP.

Biological samples were also collected by sampling 0.45 liter of vertically integrated water everyday using a tube sampler. The chlorophyll $a$ (Chl a) concentrations were measured by spectrophotometric method (Pápista et al. 2002). Samples were first filtered through GF/F filters, frozen at $-20{ }^{\circ} \mathrm{C}$ and pigments were extracted with $90 \%$ hot acetone. To measure the APA, water samples were first filtered through a $112 \mu \mathrm{m}$ mesh net to remove large zooplankton. Then, the samples were divided into two subsets according to particle size onto which the APA is associated with. Size fractionations was carried out with polycarbonate membrane filters (Millpore, Cork, Ireland) with pore sizes of $0.2 \mu \mathrm{m}$ for bacterioplankton and $2.0 \mu \mathrm{m}$ for the larger phytoplankton (Nedoma et al., 2006). The enzymatic activities were measured in the different filters by spectrophotometric method as the release of $p$-nitrophenol from the model substrate $p$-nitrophenyl phosphate (pNPP) (Gao et al., 2006). The assay mixture contained $2 \mathrm{~mL}$ of samples, $1 \mathrm{~mL}$ of $0.5 \mathrm{~mol} \mathrm{~L}^{-1}$ Tris buffer solution ( $\mathrm{pH} 8.4$ ), and $2 \mathrm{~mL}$ of freshly prepared millimolar pNPP. Samples were incubated for $6 \mathrm{~h}$ at $30{ }^{\circ} \mathrm{C}$ in the dark. The absorbance at $410 \mathrm{~nm}$ was measured with a $1 \mathrm{~cm}$ quartz cuvette in a UV-Vis recording spectrophotometer (UV-2401 PC, Shimadzu, Japan). Phosphatase activity was converted to absolute units using a standard curve based on enzymatically hydrolyzed $p$-nitrophenol. All samples were run in triplicate. The APA fractions were classified according filtrate from which they were recovered. In this study, they are referred to as total (TAPA; $112 \mu \mathrm{m}$ ), dissolved (DAPA; $0.2 \mu \mathrm{m}$ ), bacterioplanktonic (BAPA; 0.2-2.0 $\mu \mathrm{m}$ ) and phytoplanktonic APAs (PAPA; 2.0-112 $\mu \mathrm{m})$. The specific phytoplankton APA was estimated by dividing the PAPA by Chl $a$.

\section{Statistical analysis}

Test for significant differences among and between the various treatments, one-way analysis of variance (ANOVA) was employed. Post-hoc multiple comparisons of treatment means were performed by Tukey's least significant difference procedure and the standard deviation in the variations of the triplicates was calculated. Relationships between APA and P fractions were explored by Pearson's correlation coefficient. All statistical calculations were performed in Statistical Product and Service Solutions (SPSS 22.0) statistical package for personal computers, and the level of significance used was $P<0.05$ for all tests (Yockey, 2010).

\section{Results}

Physical conditions, $N: P$, and Chl a

Table 2 Mean and standard deviation of the measured physical and chemical parameters in the different turbulence treatments during the experiment which include water temperature (WT), dissolved oxygen (DO), total nitrogen (TN), the mass ratios of total nitrogen over total phosphorus (TN:TP), total dissolve nitrogen over total dissolve phosphorus (TDN:TDP), and of particulate nitrogen over particulate phosphorus (PN:PP).

\begin{tabular}{|c|c|c|c|c|}
\hline Parameter & Control & Low & Medium & High \\
\hline $\mathrm{WT}\left({ }^{\circ} \mathrm{C}\right)$ & $27.51 \pm 1.31$ & $27.51 \pm 1.36$ & $27.53 \pm 1.36$ & $27.49 \pm 1.35$ \\
\hline $\mathrm{pH}$ & $8.77 \pm 0.33$ & $8.67 \pm 0.28$ & $8.57 \pm 0.25$ & $8.53 \pm 0.23$ \\
\hline $\mathrm{DO}\left(\mathrm{mg} \mathrm{L}^{-1}\right)$ & $8.58 \pm 1.27$ & $7.71 \pm 0.43$ & $7.77 \pm 0.46$ & $7.73 \pm 0.42$ \\
\hline $\mathrm{TN}\left(\mathrm{mg} \mathrm{L}^{-1}\right)$ & $1.64 \pm 0.19$ & $1.70 \pm 0.15$ & $1.85 \pm 0.10$ & $1.83 \pm 0.08$ \\
\hline
\end{tabular}




\begin{tabular}{|c|c|c|c|c|}
\hline TN:TP & $35.19 \pm 9.93$ & $31.73 \pm 7.79$ & $30.30 \pm 5.49$ & $31.99 \pm 8.14$ \\
\hline TDN:TDP & $132.51 \pm 83.17$ & $100.13 \pm 48.32$ & $115.07 \pm 95.67$ & $88.17 \pm 33.57$ \\
\hline PN:PP & $14.67 \pm 4.98$ & $16.54 \pm 6.08$ & $17.06 \pm 6.38$ & $16.10 \pm 5.58$ \\
\hline
\end{tabular}

The water temperature ranged from 25.6 to $30.2^{\circ} \mathrm{C}$ with $\mathrm{DO}$ and $\mathrm{pH}$ higher in the control than the treatments (low, medium, and high) during the experiment (Table 2, $P>0.05$ ). The TN concentrations were also significantly higher in the treatments $\left(1.8 \pm 0.13 \mathrm{mg} \mathrm{L}^{-1}\right)$ than in the control $\left(1.6 \pm 0.19 \mathrm{mg} \mathrm{L}^{-1}\right.$, Table 2, $P<0.05)$. In addition, although TN:TP and TDN:TDP ratios were generally higher in the control than in the treatments, the differences were not significant (Table 2, $P>0.05$ ). However, the opposite was observed for the PN:PP mass ratio where it was relatively smaller in the control than in the treatments (Table 2, $P>0.05$ ).

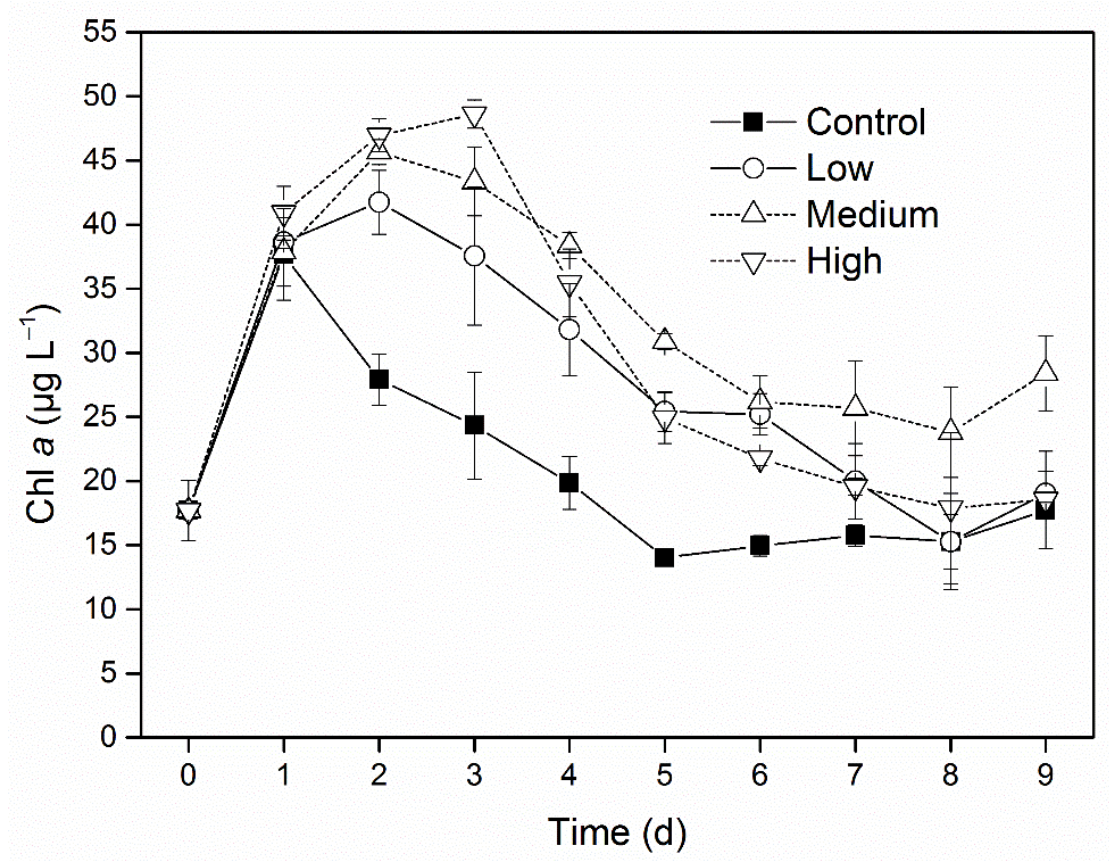

Fig. 2 Variations of Chl $a$ in the different turbulence treatments during the experiment including control (black square), low (circle), medium (triangle) and high (inverted triangle).

The Chl $a$ concentrations fluctuated significantly in the different treatments and the length of time needed to reach maximum concentrations also varied. Generally, it was observed that Chl $a$ increased the fastest to a maximum of 41.7 and $45.7 \mu \mathrm{g} \mathrm{L}^{-1}$ at day 2 in low and medium treatments while those in high took more than 3 days to reach $48.6 \mu g \mathrm{~L}^{-1}$ (Fig. 2). On the other hand, Chl $a$ in the control gradually decreased after peaking on day 1 with $37.7 \mu \mathrm{L} \mathrm{L}^{-1}$ (Fig. 2). Also, the 9-day average of pigment concentrations in the control (20.5 \pm 7.5 ) was lower compared to the treatments (low $=27.2 \pm 9.6$, medium $=31.8 \pm 9.1$, high $=29.2 \pm 12.5 \mu \mathrm{L} \mathrm{L}^{-1}$; Fig. $2, P>0.05$ ). 

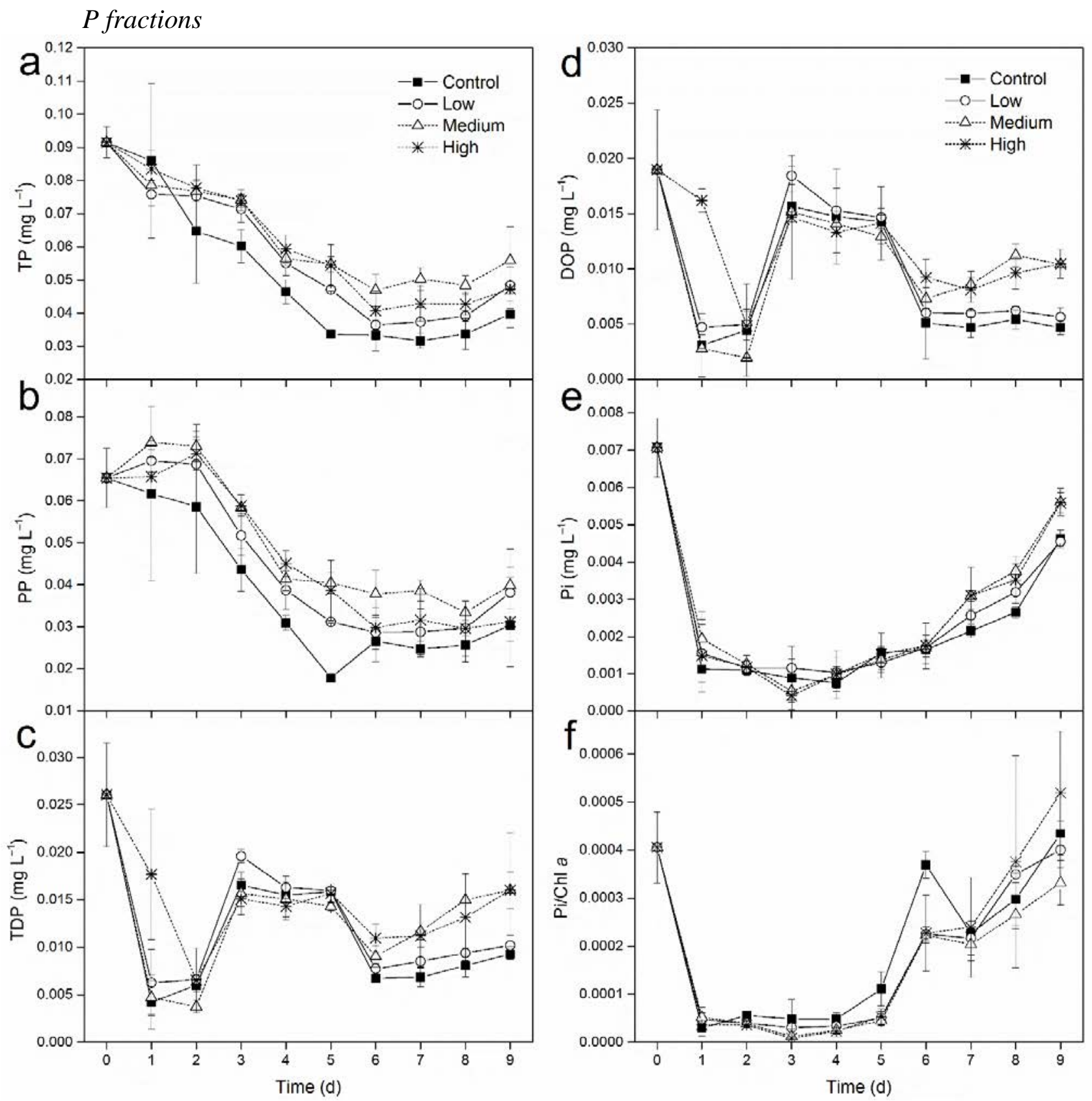

Fig. 3 Variations of phosphorus fractions (a, TP; b, PP; c, TDP; d, DOP; e, Pi) and the ratio of Pi over Chl $a$ (f) in the different turbulence treatments during the experiment. Control (black square), low (circle), medium (triangle) and high (inverted triangle). TP, total phosphorus; PP, particulate phosphorus; TDP, total dissolved phosphorus; DOP, dissolved organic phosphorus; Pi, phosphate.

TP concentrations observed ranged from 0.032 to $0.092 \mathrm{mg} \mathrm{L}^{-1}$ during the experiment. Fractions of the different forms of phosphate (TP/PP and TDP/DOP) fluctuated on the first few days of the experiment but became stable and continued to increase in the turbulent conditions after 6 days (Fig. 3). Moreover, Pi became depleted on the first 4 days but surprisingly increased again on the succeeding 4 days. In addition, recovery of the inorganic phosphate was higher in the treatments (Fig. 3e). Similarly, Pi/Chl $a$ ratio which reflects the available phosphorus per phytoplankton, drastically decreased at first but increased after 4 days, although it was smaller in the treatments than in the control from day 2 to day 6 (Fig. 3f). 

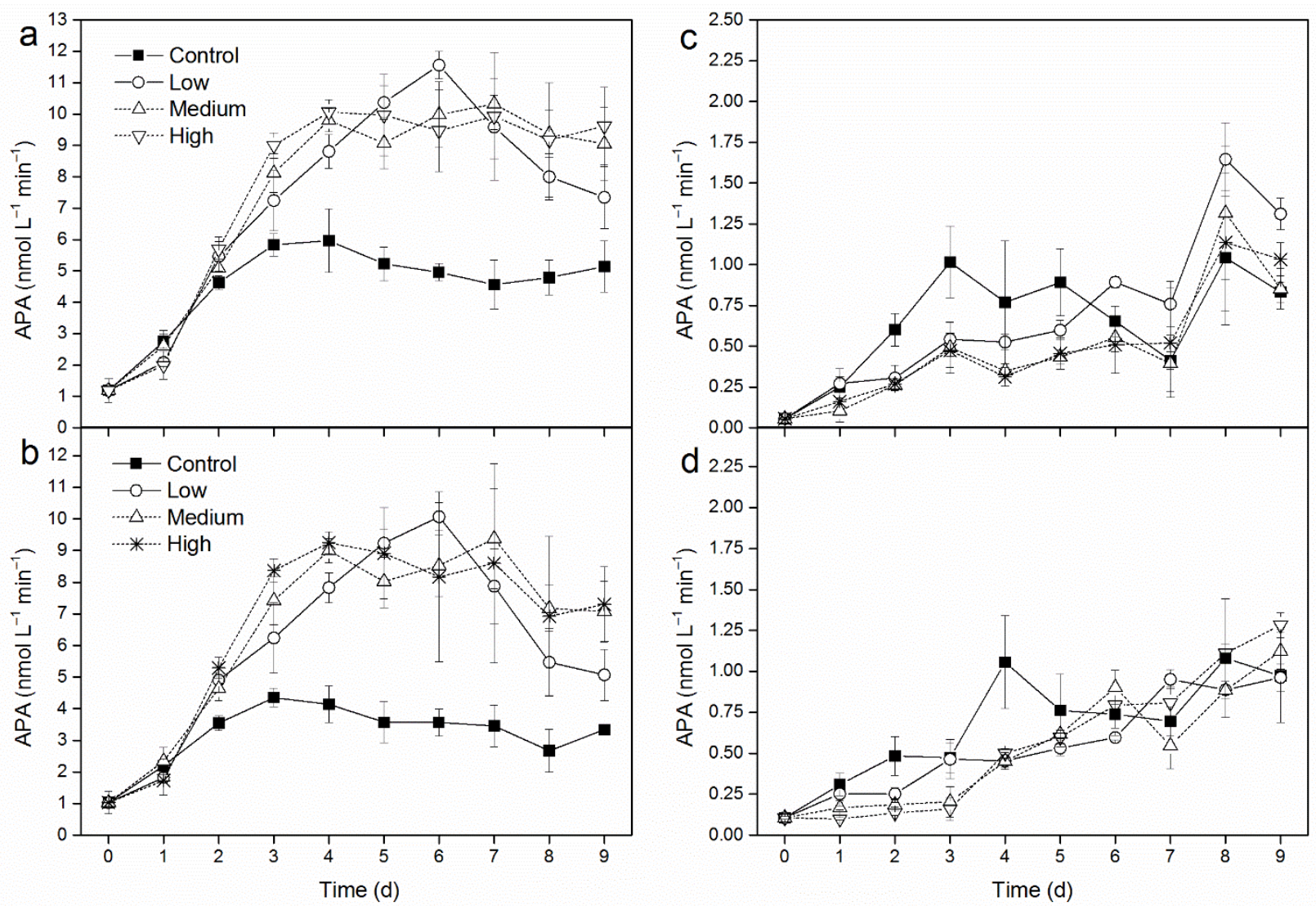

Fig. 4 Variations of alkaline phophatase activity (APA) fractions in the different turbulence treatments during the experiment. a, total APA; b, phytoplanktonic APA; c, bacterioplanktonic APA; d, dissolved APA. Control (black square), low (circle), medium (triangle) and high (inverted triangle).

Since the treatments were not supplanted with nutrients, levels of TAPA increased quickly before day 4 and then remained stable until the end of the study, except in low treatment where it exhibited stationary decrease after day 6 (Fig. 4a). Interestingly, TAPA was lower before day 2 and then became much higher in the turbulence treatments $\left(>7.2 \mathrm{nmol} \mathrm{L}^{-1} \mathrm{~min}^{-1}\right)$ the succeeding days, generally higher than in the control (4.5 $\pm 1.5 \mathrm{nmol} \mathrm{L}^{-1} \mathrm{~min}^{-1}$; Fig. 4a). During the experiment, PAPA consisted most of the TAPA (66-93\%). Like the Chl $a$, PAPA significantly increased on the first few days of incubation but slowly declined towards the end of the study. In addition, PAPA was significantly higher in the treatments, particularly in medium and high $\left(6.5 \pm 2.9\right.$ and $\left.6.6 \pm 3.0 \mathrm{nmol} \mathrm{L}^{-1} \mathrm{~min}^{-1}\right)$, than in the control $(3.2 \pm 0.98$ nmol L${ }^{-1} \mathrm{~min}^{-1}$; Fig. 4b, $\left.P<0.05\right)$. On the other hand, the remaining fractions of TAPA were shared by BAPA (3.1-21.8\%) and DAPA (1.7-22.6\%), both of which increased slowly during the experiment (Fig. 4c, d). Interestingly, compared to the PAPA, BAPA and DAPA were lower in the treatments than in the control before day 6 ( $P>0.05)$, and then became slightly higher afterwards (Fig. 4c, d). 
Table 3 Summary of the correlations of alkaline phophatase activity (APA) fractions such as total (TAPA), phytoplanktonic (PAPA), bacterioplanktonic (BAPA), dissolved (DAPA), and specific PAPA (PAPA/Chl $a$ ) on different $\mathrm{P}$ fractions. Pearson's correlation coefficient was applied and the sample number was 40.

\begin{tabular}{llllll}
\hline & TAPA & PAPA & BAPA & DAPA & Specific PAPA \\
\hline TP & $\mathbf{- 0 . 6 2}$ & $\mathbf{- 0 . 4 9}$ & $-\mathbf{0 . 7 1}$ & $\mathbf{- 0 . 8 7}$ & $\mathbf{- 0 . 8 0}$ \\
TDP & -0.18 & -0.14 & -0.22 & -0.20 & -0.16 \\
PP & $\mathbf{- 0 . 6 0}$ & $\mathbf{- 0 . 4 7}$ & $-\mathbf{0 . 7 0}$ & $\mathbf{- 0 . 8 5}$ & $\mathbf{- 0 . 8 1}$ \\
DOP & -0.081 & -0.023 & -0.24 & -0.27 & -0.14 \\
Pi & $\mathbf{0 . 3 4}$ & $\mathbf{- 0 . 3 9}$ & 0.019 & 0.12 & -0.10 \\
TN:TP & $\mathbf{0 . 5 4}$ & $\mathbf{0 . 4 1}$ & $\mathbf{0 . 6 2}$ & $\mathbf{0 . 8 0}$ & $\mathbf{0 . 7 7}$ \\
TDN:TDP & $\mathbf{- 0 . 3 3}$ & -0.30 & -0.24 & -0.26 & $\mathbf{- 0 . 3 6}$ \\
PN:PP & $\mathbf{0 . 8 0}$ & $\mathbf{0 . 7 0}$ & $\mathbf{0 . 6 8}$ & $\mathbf{0 . 7 7}$ & $\mathbf{0 . 8 9}$ \\
\hline
\end{tabular}

Bold values indicate that the correlation is significance $(P<0.05)$.

Correlations between APA and P fractions are summarized in Table 3. The TP and PP were significantly negatively correlated with all APA fractions $(P<0.001)$. The Pi on the other hand only had negative correlations with TAPA and PAPA $(P<0.05)$. However, no pattern was observed between TDP, DOP and all APA fractions $(P>0.05)$. The TN:TP and PN:PP ratios are positively correlated with all APA fractions $(P<0.001)$ while TDN:TDP ratio had significant negative correlations with TAPA and specific PAPA $(P<0.05)$.

\section{Discussion}

Although many studies have examined the relationship between APA and P (Labry et al., 2005; Tanaka et al., 2006; Cao et al., 2009a), as well as the spatial and temporal variation of APA (Zhou \& Zhou, 1997; Nedoma et al., 2006; Zhang et al., 2007), fewer studies have explored the direct relationship between turbulence and APA fractions in lakes. Results in this study showed that the phytoplanktonic APA was enhanced but bacterioplanktonic APA was reduced by turbulence in short term exposure (6 days, Fig. 4). Also, total APA was significantly correlated with phosphorus (TP, PP, and Pi) and nitrogen-phosphorus ratios (Table 3, $P<0.05$ ). This suggests that possibly, turbulence has contributed to the acceleration of the biogeochemical cycle of $\mathrm{P}$ and the growth of phytoplankton (mainly harmful Microcystis; Figs. 2, 4). The same conditions have been suggested to play a role in the formation of cyanobacterial blooms in Lake Taihu. For example, strong wind events were found to stimulate significant algal toxicity and cyanobacterial growth leading to blooms in the lake on summer (Zhu et al., 2014).

Most studies have indicated that when external soluble reactive phosphorus (SRP) are depleted, the algae and bacteria begin to synthesize AP, which are relatively stable and can hydrolyze phosphate esters as an alternative phosphorus source to compensate for the lack of P (Jansson et al., 1988; Labry et al., 2005; Nedoma et al., 2006; Cao et al., 2009a). However, the inducible threshold of APA is restricted to a certain level of Pi concentration, which depends on the ecosystem and its physico-chemical characteristics (Labry et al., 2005; G.-Tóth et al., 2011). In Taihu, when the concentration of SRP is less than $0.02 \mathrm{mg} \mathrm{L}^{-1}$ or when the mass ratio of TN over TP is above 22, the APA significantly increases (Gao et al., 2006), suggesting it is characteristic of $\mathrm{P}$ limitation. In this study, the average concentration of Pi and TN:TP ratio 
were $0.003 \pm 0.002 \mathrm{mg} \mathrm{L}^{-1}$ and 32:1, respectively. Therefore, to compensate for the lack of P, AP was naturally synthesized to hydrolyze organic P (Fig. 4). Moreover, the specific activity of alkaline phosphatase (APA/Chl $a$ ) has been suggested to be a good indicator of $\mathrm{P}$ limitation for algal growth (Nedoma et al., 2006; Tanaka et al., 2006; Ivancic et al., 2012).

During the experiment, the harmful cyanobacterium Microcystis was always the dominant species in all treatments (except in high after 8 days). Also, phytoplanktonic APA always dominated the total APA, which is also widely observed in lakes (Cao et al., 2009a; Cao et al., 2010) and in coastal waters (Jamet et al., 1997; Labry et al., 2005). However, unlike APA, bacterioplanktonic and dissolved APA were reduced before the $6^{\text {th }}$ days under turbulent conditions (Fig. 4). Turbulence, which causes mixing and thus affecting the physic-chemical properties of the water column, increases the diffusion rate in the cell surface (reviewed by Guasto et al., 2012) and enhances the uptake of nutrients (Bergstedt et al., 2004; Honzo \& Wuest, 2008; Prairie et al., 2012). These in turn accelerates the reduction of nutrient in water. However, in the process of P uptake, the competitive success of bacteria versus phytoplankton for Pi has been widely confirmed under turbulent conditions at low Pi concentration due to surface to volume ratio (Currie \& Kalff, 1984a; Drakare, 2002; Honzo \& Wuest, 2008). Therefore, phytoplankter were not getting sufficient $\mathrm{P}$ to support their growth by competing with bacteria, especially with turbulence. Under these conditions, phytoplankton may also up regulate proteins and enzymes to aid in P scavenging (Dyhrman \& Ruttenberg, 2006). Another possibility to overcome $P$ limitation is the ability of phytoplankton to lower their physiological P demand by as much as 50\% (reviewed by Ivancic et al., 2012). However, under external P limitation, phytoplankton depends more directly on the internal rather than external $\mathrm{P}$ concentrations produced from accumulated and stored excess P (Litchman \& Nguyen, 2008). The most effective way is to decompose the intracellular stored organic $\mathrm{P}$ to compensate for $\mathrm{P}$ deficiency, and alkaline phosphatase plays a key role in this process (Feuillade et al., 1990), with significant positively corelations between PN:PP and all APA fractions (Table 3, $P<0.001$ ) . On the other hand, the experiment showed that the available phosphorus per phytoplankton ( $\mathrm{Pi} / \mathrm{Chl} a$ ratio) was smaller in the turbulence treatments than in the control from day 2 to day 6 (Fig. 3f). Interestingly, at the same time (that is from day 2 to day 6), phytoplanktonic APA increased much faster in the turbulence treatments than in the control (Fig. 4b). This may explain why phytoplanktonic APA was enhanced but the bacterioplanktonic APA were reduced before 6 days by turbulence. However, as the available phosphorus depleted in water, the bacterioplankton also have to synthesize AP to hydrolyze the stored P in cells (Fig. 4c) resulting to gradual slow increase towards the end of the experiment. Furthermore, when the intracellular stored organic phosphorus reservoirs were depleted, the AP had to be released to hydrolyze DOP in the water so causing that the dissolved APA to increase (Fig. 4d). Consequently, turbulence promoted the APA and increased the Pi concentration that accelerated the growth of harmful algae (Figs. 2-4). These results are consistent with previous observations in Taihu where the maximal values of APA were detected in western estuary (river estuary) and central region of the lake (Gao et al., 2006; Nu et al., 2009), which are known to be strongly influenced by turbulence. Similarly, APA is also enhanced by wind wave turbulence when the artificial sand barrier was opened in coastal waters (Panosso \& Esteves, 2000).

However, even though fractionation was performed to determine the relative APA contribution of the different groups, several caveats are still needed to be considered which may affect the results such as overlapping sized and breaking of cells (Labry et al., 2005). Specifically, the proportion of particulatebound bacteria was not assessed in this study and the filtration procedure was unable to evaluate the relative contribution of the community to total APA. However, the proportion of BAPA which only makes up a small portion (1.8-22.6\%) of the total APA could also suggest that the attached bacteria only represented a small part of phytoplanktonic APA. Consequently, it can be assumed that the 2-112 $\mu \mathrm{m}$ size fraction corresponded essentially to the phytoplankton and the $0.2-2 \mu \mathrm{m}$ size fraction to bacterioplankton.

Because Lake Taihu is very shallow, it is strongly influenced by wind wave turbulence and the turbulent kinetic-energy content are much higher than those in stratified deep lakes and even in the open ocean (G.-Tóth et al. 2011). However, In Taihu, the cyanobacterial blooms have occurred every summer and threaten the supply of drinking water and fisheries-related products for more than 8 million people, 
resulting to great economic losses (Qin et al. 2007). This study has demonstrated that turbulence is an important driver of biogeochemical perturbations, and can accelerate the biogeochemical cycle of $\mathrm{P}$ which have implications on the dynamics of harmful algal blooms. Thus, it should be carefully considered and integrated in bloom management and forecasting.

\section{Conclusion}

Determination of alkaline phosphatase activity (APA) is considered to be a convenient and useful proxy for detecting $\mathrm{P}$ deficiency in Lake Taihu. This study based on mesocosm experiment demonstrated that turbulence promoted the phytoplanktonic APA and accelerated the biogeochemical cycle of P. Also, turbulence promoted the growth of harmful algae (mainly Microcystis), which is beneficial to harmful cyanobacterial blooms. Our results contribute to the better understanding the P strategies of phytoplankton and bacterioplankton in turbulent environment.

\section{Acknowledgements}

We appreciate the very thorough and constructive reviews provided by two anonymous reviewers. This research was supported by the National Science Foundation of China (41230744). 


\section{References}

Barton, A. D., B. A. Ward, R. G. Williams \& M. J. Follows, 2014. The impact of fine-scale turbulence on phytoplankton community structure. Limnology and Oceanography: Fluids and Environments 4(1): 34-49.

Bergstedt, M. S., M. M. Hondzo \& J. B. Cotner, 2004. Effects of small scale fluid motion on bacterial growth and respiration. Freshwater Biology 49(1): 28-40.

Cao, X., C. Song \& Y. Zhou, 2009a. Limitations of using extracellular alkaline phosphatase activities as a general indicator for describing $\mathrm{P}$ deficiency of phytoplankton in Chinese shallow lakes. Journal of Applied Phycology 22(1): 33-41.

Cao, X., C. Song, Y. Zhou, A. Štrojsová, P. Znachor, E. Zapomělová \& J. Vrba, 2009b. Extracellular phosphatases produced by phytoplankton and other sources in shallow eutrophic lakes (Wuhan, China): taxon-specific versus bulk activity. Limnology 10(2): 95-104.

Cao, X., C. Song \& Y. Zhou, 2010. Limitations of using extracellular alkaline phosphatase activities as a general indicator for describing $\mathrm{P}$ deficiency of phytoplankton in Chinese shallow lakes. Journal of Applied Phycology 22(1): 33-41.

Cardoso, L. S. \& D. M. Marques, 2009. Hydrodynamics-driven plankton community in a shallow lake. Aquatic ecology 43(1): 73-84.

Carpenter, S. R., 2008. Phosphorus control is critical to mitigating eutrophication. Proceedings of the National Academy of Sciences of the United States of America 105(32): 11039-11040.

Clarke, R. D., E. J. Buskey \& K. C. Marsden, 2005. Effects of water motion and prey behavior on zooplankton capture by two coral reef fishes. Marine Biology 146(6): 1145-1155.

Currie, D. J. \& J. Kalff, 1984a. Can bacteria outcompete phytoplankton for phosphorus? a chemostat test. Microbial Ecology 10(3): 205-216.

Currie, D. J. \& J. Kalff, 1984b. The relative importance of bacterioplankton and phytoplankton in phosphorus uptake in freshwater. Limnology and Oceanography 29(2): 311-321.

Drakare, S., 2002. Competition between picoplanktonic cyanobacteria and heterotrophic bacteria along crossed gradients of glucose and phosphate. Microbial Ecology 44(4): 327-335.

Dyhrman, S. T. \& K. C. Ruttenberg, 2006. Presence and regulation of alkaline phosphatase activity in eukaryotic phytoplankton from the coastal ocean: implications for dissolved organic phosphorus remineralization. Limnology and Oceangraphy 51(3): 1381-1390.

Feuillade, J., M. Feuillade \& P. Blanc, 1990. Alkaline phosphatase activity fluctuations and associated factors in a eutrophic lake dominated by Oscillatoria rubescens. Hydrobiologia 207(1): 233-240.

G.-Tóth, L., L. Parpala, C. Balogh, I. Tátrai \& E. Baranyai, 2011. Zooplankton community response to enhanced turbulence generated by water-level decrease in Lake Balaton, the largest shallow lake in Central Europe. Limnology and Oceanography 56(6): 2211-2222.

Gao, G., G. W. Zhu, B. Q. Qin, J. Chen \& K. Wang, 2006. Alkaline phosphatase activity and the phosphorus mineralization rate of Lake Taihu. Science in China Series D 49: 176-185.

Guasto, J. S., R. Rusconi \& R. Stocker, 2012. Fluid mechanics of planktonic microorganisms. Annual Review of Fluid Mechanics 44(1): 373-400.

Härkönen, L., Z. Pekcan-Hekim, N. Hellén, A. Ojala \& J. Horppila, 2014. Combined effects of turbulence and different predation regimes on zooplankton in highly colored water-Implications for environmental change in lakes. Plos one 9(11): e111942.

Hernandez, I., F. X. Niell \& B. A. Whitton, 2002. Phosphatase activity of benthic marine algae. An overview. Journal of Applied Phycology 14(6): 475-487.

Honzo, M. \& A. Wüest, 2008. Do microscopic organisms feel turbulent flows. Environmental Science and Technology 43: 764-768.

Istvánovics, V., 2008. The role of biota in shaping the phosphorus cycle in lakes. Freshwater Reviews 1(2): 143174.

Ivancic, I., J. Godrijan, M. Pfannkuchen, D. Maric, B. Gasparovic, T. Djakovac \& M. Najdek, 2012. Survival mechanisms of phytoplankton in conditions of stratification-induced deprivation of orthophosphate: Northern Adriatic case study. Limnology and Oceanography 57(6): 1721-1731.

Jamet, D., C. Amblard \& J. Devaux, 1997. Seasonal changes in alkaline phosphatase activity of bacteria and microalgae in Lake Pavin (Massif Central, France). Hydrobiologia 347: 185-195.

Jansson, M., H. Olsson \& K. Pettersson, 1988. Phosphatases; origin, characteristics and function in lakes. Hydrobiologia 170: 157-175. 
Kundu, P. K. \& I. M. Cohen, 2010. Fluid mechanics. San Diego Academic Press, San Diego.

Labry, C., D. Delmas \& A. Herbland, 2005. Phytoplankton and bacterial alkaline phosphatase activities in relation to phosphate and DOP availability within the Gironde plume waters (Bay of Biscay). Journal of Experimental Marine Biology and Ecology 318(2): 213-225.

Litchman, E. \& B. L. V. Nguyen, 2008. Alkaline phosphatase activity as a function of internal phosphorus concentration in freshwater phytoplankton. Journal of Phycology 44(6): 1379-1383.

Meseck, S. L., J. H. Alix, G. H. Wikfors \& J. E. Ward, 2009. Differences in the soluble, residual phosphate concentrations at which coastal phytoplankton species up-regulate alkaline-phosphatase expression, as measured by flow-cytometric detection of ELF-97A fluorescence. Estuaries and Coasts 32(6): 1195-1204.

Nedoma, J., J. C. Garcia, M. Comerma, K. Šimek \& J. Armengol, 2006. Extracellular phosphatases in a Mediterranean reservoir: seasonal, spatial and kinetic heterogeneity. Freshwater Biology 51(7): 1264-1276.

Nu, L., W. Hu, J. Deng, S. Zhai, X. Chen \& X. Zhou, 2009. Patial distribution characteristics and ecological significance of alkaline phosphatase in water column of Lake Taihu. Environmental Science 30(10): 2898-2903. (in Chinese)

Panosso, R. \& F. Esteves, 2000. Effects of disturbance on phosphorus turnover and plankton dynamics. Journal of Plankton Research 22(3): 589-595.

Pápista, É., É. Ács \& B. Böddi, 2002. Chlorophyll-a determination with ethanol - a critical test. Hydroiologia 485:191-198

Pekcan-Hekim, Z., L. Joensuu, J. Horppila \& J. Grant, 2013. Predation by a visual planktivore perch (Perca fluviatilis) in a turbulent and turbid environment. Canadian Journal of Fisheries and Aquatic Sciences 70(6): 854859.

Peters, F. \& J. M. Redondo, 1997. Turbulence generation and measurement: application to studies on plankton. Scientia Marina 61: 205-228.

Prairie, J. C., K. R. Sutherland, K. J. Nickols \& A. M. Kaltenberg, 2012. Biophysical interactions in the plankton: a cross-scale review. Limnology and Oceanography: Fluids and Environments 2: 121-145.

Qin, B. Q., P. Z. Xu, Q. L. Wu, L. C. Luo \& Y. L. Zhang, 2007. Environmental issues of Lake Taihu, China. Hydrobiologia 581: 3-14.

Qin, B. Q., G. W. Zhu, G. Gao, Y. L. Zhang, W. Li, H. W. Paerl \& W. W. Carmichael, 2010. A drinking water crisis in Lake Taihu, China: linkage to climatic variability and lake management. Environmental Management 45(1): 105112.

Raheb, J., S. Naghdi \& K. P. Flint, 2006. Alkaline phosphatase activity of Flexibacter chinensis under starvation stress in water microcosms. Enzyme and Microbial Technology 40(1): 13-16.

Rengefors, K., K. Pettersson, T. Blenckner \& D. M. Anderson, 2001. Species-specific alkaline phosphatase activity in freshwater spring phytoplankton: Application of a novel method. Journal of Plankton Research 23(4): 435-443.

Sanford, L. P., 1997. Turbulent mixing in experimental ecosystem studies. Marine Ecology Progress Series 161: 265-293.

Tanaka, T., P. Henriksen, R. Lignell, K. Olli, J. Seppala, T. Tamminen \& T. F. Thingstad, 2006. Specific affinity for phosphate uptake and specific alkaline phosphatase activity as diagnostic tools for detecting phosphorus-limited phytoplankton and bacteria. Estuaries and Coasts 29: 1226-1241.

Tanaka, T., T. F. Thingstad, T. Lovdal, H.-P. Gressart, A. Larsen, M. Allgaier, M. Meyerhöfer, K. G. Schulz, J. Wohlers, E. Zöllner \& U. Riebesell, 2008. Availability of phosphate for phytoplankton and bacteria and of labile organic carbon for bacteria at different pCO2 levels in a mesocosm study. Biogeosciences 5: 669-678.

Wetzel, R. G., 2001. Limnology: lake and river ecosystems. Academic Press, New York. p: 85-111.

Wu, T., B. Qin, G. Zhu, L. Luo, Y. Ding \& G. Bian, 2013. Dynamics of cyanobacterial bloom formation during short-term hydrodynamic fluctuation in a large shallow, eutrophic, and wind-exposed Lake Taihu, China. Environmental Science and Pollution Research 20(12): 8546-8556.

Yockey, R. D., 2010. SPSS demystified: A step by step approach. Prentice Hall Press, Upper Saddle River, NJ.

Zhang, T., X. Wang \& X. Jin, 2007. Variations of alkaline phosphatase activity and P fractions in sediments of a shallow Chinese eutrophic lake (Lake Taihu). Environmental Pollution 150(2): 288-294.

Zhu, M., H. W. Paerl, G. Zhu, T. Wu, W. Li, K. Shi, L. Zhao, Y. Zhang, B. Qin \& A. M. Caruso, 2014. The role of tropical cyclones in stimulating cyanobacterial (Microcystis spp.) blooms in hypertrophic Lake Taihu, China. Harmful Algae 39: 310-321.

Zhou, Y. Y. \& X. Y. Zhou, 1997. Seasonal variation in kinetic parameters of alkaline phosphatase activity in a shallow Chinese freshwater lake (Donghu Lake). Water Research 31(5): 1232-1235. 